\title{
Ovine prenatal growth restriction impacts glucose metabolism and body composition throughout life in both sexes
}

\author{
Jacqueline M Wallace¹, John S Milne', Raymond P Aitken, Graham W Horgan² and \\ Clare L Adam ${ }^{1}$ \\ ${ }^{1}$ Rowett Institute, University of Aberdeen, Aberdeen, UK and ${ }^{2}$ Biomathematics and Statistics Scotland, \\ Aberdeen, UK \\ Correspondence should be addressed to J M Wallace; Email: Jacqueline.Wallace@abdn.ac.uk
}

\begin{abstract}
Low birthweight is a risk factor for later adverse health. Here the impact of placentally mediated prenatal growth restriction followed by postnatal nutrient abundance on growth, glucose metabolism and body composition was assessed in both sexes at key stages from birth to mid-adult life. Singleton-bearing adolescent dams were fed control or high nutrient intakes to induce normal or growthrestricted pregnancies respectively. Restricted lambs had $\sim \mathbf{4 0} \%$ reduced birthweight. Fractional growth rates were higher in restricted lambs of both sexes predominantly during suckling/juvenile phases. Thereafter, rates and patterns of growth differed by sex. Absolute catch-up was not achieved and restricted offspring had modestly reduced weight and stature at mid-adulthood necropsy ( 109 weeks). Dual-energy X-ray absorptiometry revealed lower bone mineral density in restricted vs normal lambs at 11, 41, 64 and 107 weeks, with males $>$ females from 41 weeks onwards. Body fat percentage was higher in females vs males throughout, in restricted vs normal lambs at weaning (both sexes) and in restricted vs normal females at mid-adulthood. Insulin secretion after glucose challenge was greater in restricted vs normal of both sexes at 7 weeks and in restricted males at 32 weeks. In both sexes, fasting glucose concentrations were greater in restricted offspring across the life course, while glucose area under the curve after challenge was higher in restricted offspring at 32, 60, 85 and 106 weeks, indicative of persistent glucose intolerance. Therefore, prenatal growth restriction has negative consequences for body composition and metabolism throughout the life course with the effects modulated by sex differences in postnatal growth rates, fat deposition and bone mass accrual.

Reproduction (2018) 156 103-119
\end{abstract}

\section{Introduction}

Inadequate fetal growth velocity leading to prenatal growth restriction, early delivery and low birthweight predicts immediate survival in the neonatal period (Bernstein et al. 2000) and is widely considered a risk factor for poor metabolic health and inappropriate body composition in later life (Barker 2006, Ibáñez et al. 2006, Crane et al. 2016). The medium to longer term health risks associated with low birthweight are hypothesised to be exacerbated when the newborn is exposed to an unlimited postnatal calorie rich environment, and thereby has the potential to exhibit rapid compensatory growth: this is the common scenario in the developed world (Gluckman \& Hanson 2008). A recent umbrella review of systematic reviews and meta-analyses investigating birthweight in relation to a vast array of health sequelae in later life suggests that the range of outcomes consistently associated with birthweight is narrower than originally described (Belbasis et al. 2016). Nevertheless, the authors found evidence of highly robust and convincing associations between low birthweight and the risk of childhood stunting, and between stepwise increases in birthweight and bone mineral density (BMD) in adults. Similarly, low birthweight is an established risk factor for adultonset type II diabetes (Harder et al. 2007, Whincup et al. 2008), and this relationship is independent of current BMI (Katanoda et al. 2017). Relationships between size at birth and subsequent adiposity, across the birthweight range and for low birthweight individuals specifically, are less clear and often contradictory (Araújo de Franca et al. 2014). This in part reflects the widespread use of anthropometric measures as proxies for abdominal fatness rather than more accurate imaging methods, but as with all epidemiological research, heterogeneity and potential confounding by environmental and lifestyle factors, arising between birth and the point of measurement, are also likely to be a major issue. Moreover, there is a paucity of longitudinal studies that have followed the temporal development of the aforementioned health outcomes in prenatally growthrestricted babies at key stages across the life course.

These deficits can in part be addressed by using animal models. As more than $60 \%$ of human prenatal 
growth restriction is secondary to uteroplacental insufficiency (Ghidini 1996), a number of ovine paradigms of placentally mediated fetal growth restriction have been developed (Morrison 2008). The sheep is the species of choice as the ontogeny of key metabolic organs is similar, fat deposition commences in fetal life and birthweight of singletons is comparable to the human, after a relatively long gestation (Green et al. 2010, Ojha \& Budge 2012). Moreover, adult size and body fatness are analogous. Although ovine models of utero-placental insufficiency have been extensively used to characterise the impact of poor fetal nutrient supply on growth, development and metabolism in utero and to interrogate the underlying mechanisms at a whole body and tissue level, there is a paucity of studies investigating the postnatal consequences of feto-placental growth restriction beyond the neonatal period. This in part reflects the difficulties involved in keeping these small and fragile lambs alive. The notable exceptions are the premating carunclectomy (De Blasio et al. 2007a) and overnourished adolescent models. The latter model is our focus here: it employs assisted conception procedures, which restrict pregnancies to a single embryo/fetus and maximises offspring genetic homogeneity, and, nutritional manipulation of gestational weight gain in young dams to prioritise their own growth and adiposity to the detriment of the conceptus (Wallace et al. 1996). Relative to optimally fed controls, overnourishing adolescents in this way leads to early defects in placental development and by mid-pregnancy uterine blood flow is attenuated (Wallace et al. 2008). Reductions in placental size and fetal growth velocity become apparent throughout the final third of pregnancy (Carr et al. 2012) and on average lambs are $\sim 30 \%$ lighter at birth (reviewed in Wallace 2016). The model also replicates the prematurity and perinatal mortality common in human fetal growth restriction. Viable lambs are born spontaneously as early as day 135 of pregnancy (term $=145$ days in optimally fed controls) and characteristically average gestation length is between 3 and 5 days shorter. The shift in nutrient partitioning priorities in overnourished dams also impacts colostrum supply at birth and initial lactation and the formation of an adequate ewe-lamb bond is often delayed. However, a preemptive neonatal care protocol ensures that the most premature and growth-restricted individuals usually survive.

Our aim here was to use the overnourished adolescent model to longitudinally examine the impact of poor prenatal growth followed by unlimited postnatal nutrition on growth, glucose metabolism and body composition in both male and female offspring at multiple time points between birth and mid-adult life. This study addressed the hypothesis that prenatally growth-restricted offspring would display rapid postnatal growth when released from the nutritional constraint of their in utero environment, with consequences for their glucose metabolism and body composition; further, the pattern of these effects is likely to vary with age and sex but would ultimately contribute to a less healthy adult phenotype.

\section{Methods}

\section{Experimental design}

\section{Pregnancy establishment and nutritional management}

All procedures were licensed under the UK Animals (Scientific Procedures) Act of 1986 and approved by the Rowett Institute's Ethical Review Committee. Ewes were housed in individual open-wide bar pens that facilitated nose-to-nose contact with neighbouring animals, under natural lighting conditions at $57^{\circ} \mathrm{N}, 2^{\circ} \mathrm{W}$. Singleton pregnancies were generated following superovulation and laparoscopic intrauterine insemination (single sire) of adult donor ewes and transfer of the resulting embryos into adolescent recipients ( 8.5 months old) of similar initial weight and adiposity, as described previously (Wallace et al. 1997). At embryo transfer, recipients had a mean live weight ( \pm S.E.M.) of $46.6 \pm 1.09 \mathrm{~kg}$, adiposity score of $2.3 \pm 0.04$ units (equivalent to $23 \%$ body fat, based on a fivepoint scale, where one $=$ emaciated and five $=$ extremely obese Russel et al. 1969), and ovulation rate of $2.0 \pm 0.16$. Beginning immediately after embryo transfer and throughout pregnancy, adolescent recipients were offered a control or high level of the same complete diet supplying $12 \mathrm{MJ}$ of metabolisable energy (ME) and $140 \mathrm{~g}$ of crude protein per $\mathrm{kg}$ (see Wallace et al. 2006 for details of diet composition and analyses). The dietary level in the control group was calculated to maintain initial maternal adiposity throughout gestation and to provide $100 \%$ of the estimated ME and protein requirements of the adolescent sheep carrying a singleton fetus according to stage of pregnancy (AFRC 1993; normal foeto-placental growth). In contrast, the high ration was designed to promote continued maternal growth and increasing adiposity at the expense of the conceptus (feto-placental growth - restricted): to achieve this embryo, recipients had the ration increased over a 2 -week period until the daily food refusal was $\sim 15 \%$ of the total offered (ad libitum intakes). These animals were considered overnourished $(\sim 2.25 \times$ control). All ewes were weighed and external adiposity score assessed fortnightly throughout pregnancy. Viable pregnancies as determined by transabdominal ultrasound were established in 24 control and 27 overnourished dams.

\section{Parturition management and neonatal care}

Since overnourished adolescents of this genotype consistently deliver early, all ewes were continuously supervised throughout the expected delivery period from day 135 of gestation until after the last control birth on day 146. A standardised proactive regimen of neonatal care was used to avert high neonatal mortality due to prematurity and impaired passive immunity and/or low nutrient intake secondary to inadequate colostrum supply. For all lambs, irrespective of maternal nutritional treatment, this included measuring colostrum yield at birth, ensuring adequate colostrum 
intake, frequent weighing to monitor suckling behaviour and appropriate weight gain, and prophylactic antibiotic treatment for 5 days as described previously (Wallace et al. 2014a, Carr et al. 2016). It is appreciated that antibiotic treatment may impact the developing neonatal microbiome with potential follow on consequences for metabolic health and thus all lambs received the antibiotics prophylactically irrespective of prematurity or birthweight. Colostrum immunoglobulin G (IgG) content was determined using an ovine-specific ELISA as described previously: intra- and inter-assay coefficients of variation were $<5 \%$. Lambs that failed to gain weight during any 8 -h period within the first 5 days after birth were offered further supplementary colostrum (first $24 \mathrm{~h}$ ) or ewe milk to ensure survival. After the placenta was delivered, its weight was recorded and the individual cotyledons dissected, counted and weighed. Two lambs died in the early neonatal period and 49 lambs entered the postnatal part of the study, comprising 12 males and 12 females from the optimally nourished control group, and 9 males and 16 females from the overnourished group.

\section{Postnatal management, growth and body composition measures}

Following parturition, all ewes were offered the complete diet to appetite (i.e. ad libitum) to maximize milk availability. For the control group, this was achieved stepwise over a period of approximately 10 days. Offspring (lamb) weight and height at the shoulder were measured weekly throughout the 11-week lactation during which time the lambs had access to their mother's feed hoppers. Males remained gonad intact throughout. After weaning, the lambs remained in their original pens and received the complete diet ad libitum with individual feed allowances adjusted twice weekly to maintain $\sim 10 \%$ daily feed refusal. Weight and height continued to be recorded at weekly intervals during this juvenile period until 29 weeks of age. Thereafter, offspring weight/height was measured less frequently ( 3-week intervals) until a more detailed anthropometric assessment, which additionally included crown-rump length and girth at the umbilicus and chest, was performed pre-necropsy at 108 (females) or 109 (males) weeks of age. The sequential measurements of height and weight were both influenced by the husbandry/welfare requirement to shear the animals (at 30, 65 and 102 weeks). Weight change was further influenced by the requirement to fast/ re-aliment the animals for the metabolic challenges detailed below. Consequently, absolute and fractional growth rates for weight and height were assessed during periods when the data were continuous and the animals were not undergoing these procedures. While animals continued to grow, absolute growth rate (AGR) was calculated as the slope of the line of best fit within a given period, determined by linear regression analysis. Overall fractional growth rate (FGR, \% per day) within any defined period was calculated by expressing the gain in weight (or height) as a proportion of baseline weight at the start of the period, divided by the time span of the period. During the first 29 weeks of postnatal life, current FGR (cFGR) was calculated as the AGR for 0-77 or 81-203 days divided by the value of a parameter (weight or height) at the start of each 7 day period.
A detailed assessment of body composition (fat, lean and bone mass) was determined by dual-energy X-ray absorptiometry (DEXA) under general anaesthesia, induced and maintained using isoflurane in a mixture of oxygen and nitrous oxide (Adam et al. 2012). Animals were imaged lying prone in a Norland XR-26 Mark II analyser (Norland Corporation, Fort Atkinson, WI, USA) at 11, 41, 64 and 107 weeks of age. Scan duration was 15-20 min and animals were standing and eating their delayed morning feed within $15 \mathrm{~min}$ of general anaesthesia ceasing. The coefficients of variation for DEXA measurement of whole body fat and lean mass were less than $4 \%$.

Necropsy was performed at 109-110 weeks of age. Euthanasia was achieved by i.v. administration of an overdose of sodium pentobarbitone $(30-40 \mathrm{~mL}$ Euthesate; $200 \mathrm{mg}$ pentobarbitone/mL; Willows Francis Veterinary, Crawley, UK) and exsanguination (by severing the main vessels of the neck). Major organs were dissected and weighed as detailed previously (Caton et al. 2009).

\section{Glucose tolerance test, metabolite and hormone analysis}

Offspring underwent intravenous glucose tolerance tests (GTTs) at 7, 32, 60, 85 and 106 weeks of age as previously described for suckling (Wallace et al. 2014a) and adult life stages (Wallace et al. 2010). Briefly, at the 7-week stage, offspring were fasted for $3 \mathrm{~h}$ prior to and throughout the test by blocking access to their mother's udder using an udder cover, and glucose was administered at $0.25 \mathrm{~g} / \mathrm{kg}$ body weight over $2 \mathrm{~min}$. At all subsequent life-stages, offspring received their normal ration at 15:00 h on the day prior to the test. Any residual food was removed an hour later and the animals fasted until the test had been completed the following afternoon. For these tests, glucose was administered at $10: 30 \mathrm{~h}$ at $0.5 \mathrm{~g} / \mathrm{kg}$ body weight. Blood samples were collected at $-30,-15,0,+5,+10,+15$, $+30,+45,+60,90$ and +120 min at 7 weeks of age and a further sample was collected at $+180 \mathrm{~min}$ at all other stages. The resultant plasma was analysed for glucose and insulin. Plasma glucose levels were determined using a dual biochemistry analyser (Model 2700, Yellow Springs Instruments, Yellow Springs, $\mathrm{OH}, \mathrm{USA}$ ) and variation between duplicates was $<3 \%$. Plasma insulin was determined in duplicate using a double antibody radioimmunoassay as previously described (MacRae et al. 1991) for which the limit of sensitivity was $0.08 \mathrm{ng} / \mathrm{mL}$ and inter- and intra-assay coefficients of variation $<8 \%$. Fasting levels and areas under the glucose and insulin response curve (AUC) were determined. AUC calculated as integrated plasma concentrations following glucose administration (5-20 min first phase and 5-120 or 5-180 min overall, for 7 weeks vs all other stages respectively) above the mean pre-GTT ( -30 to $0 \mathrm{~min})$ concentrations.

\section{Statistical analysis}

Data are presented as means \pm S.E.M. and all statistical comparisons were made using Minitab (version 17; Minitab Inc., State College, PA, USA). Depending on the comparison and ANOVA model being used all data were checked for normality for each sex separately or for the sexes combined 

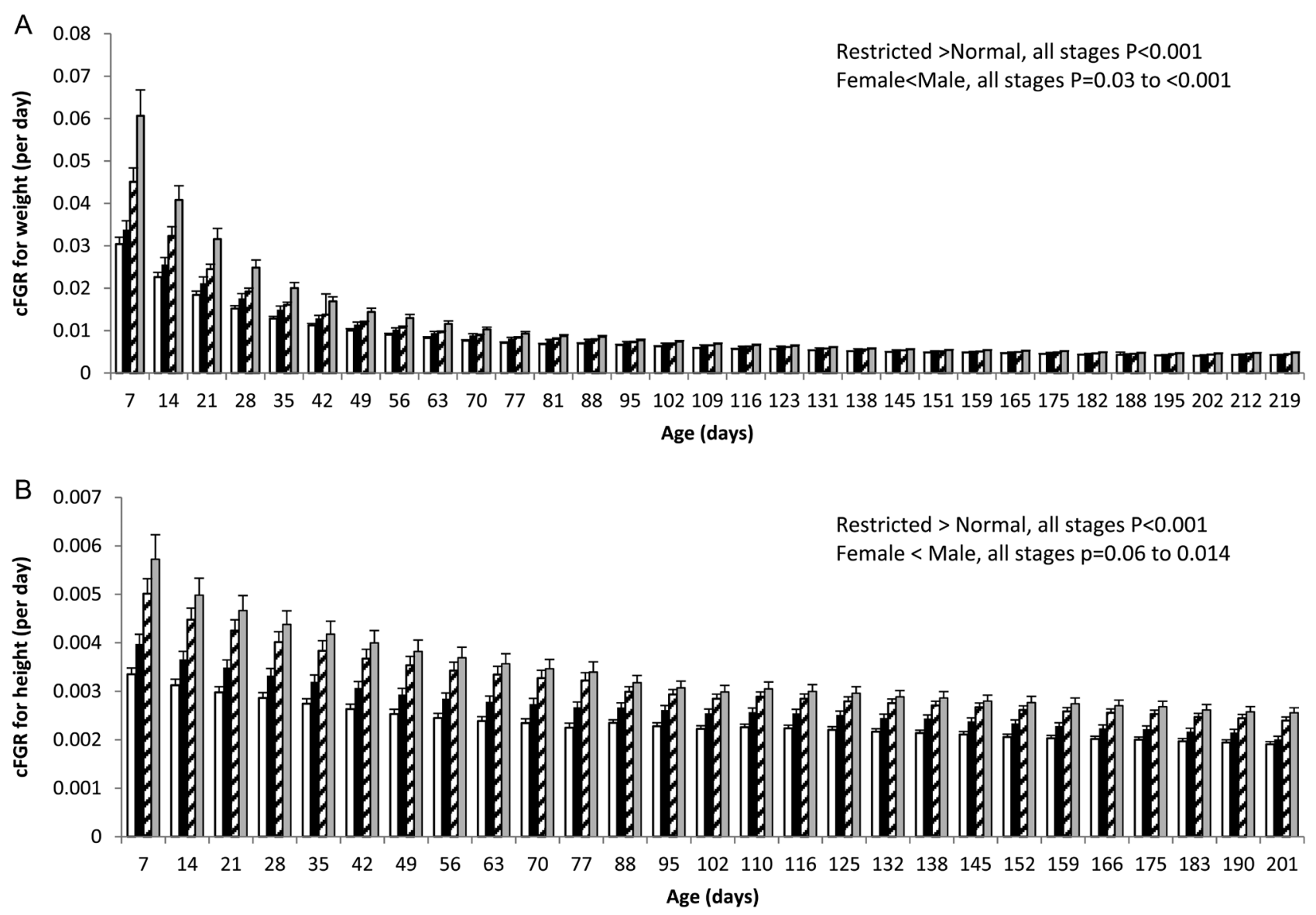

Figure 1 Effect of prenatal growth category and sex on postnatal growth rate, namely cFGR for (A) weight and (B) height in growth-restricted female (hatched bars) and male (grey bars) lambs compared with normal birthweight female (open bars) and male (solid-black bars) lambs for 7-day periods from birth until adolescence. Values are mean \pm S.E.M. cFGR, current fractional growth rate.

using an Anderson-Darling test. Where the $P$ value was $<0.05$, this was due to positively skewed distributions and so the data were log transformed before analysis. Offspring data at birth and variables examined at a defined age thereafter were analysed using one-way ANOVA for each sex separately, and by a general linear model (GLM) ANOVA to determine the effects of maternal nutrition (and thereby prenatal growth status) and sex and their potential interaction (e.g. Tables 1 and 2). Offspring variables measured at several ages, namely the body composition and glucose tolerance data, were primarily analysed using a mixed effects repeated-measures model for each sex separately, with offspring number (ID) as a random factor and maternal nutrition/prenatal growth status as a fixed factor, to determine the effect of prenatal growth status and age, and their potential interaction (Figs 2, 3, 4 and Table 3). Post hoc comparison between groups at all ages was by Fishers least significant difference (LSD) method using the SED for comparison of means. Within-group and within-sex assessments of the change in body composition parameters between DEXA scans were analysed using paired Student's t-tests. Categorical data were compared by binary logistic regression. Pearson product-moment correlation coefficients were used to explore relationships between variables where indicated and data are presented as correlation coefficients $(r)$ and $P$ values. Statistical significance was taken as $P \leq 0.05$.

As lambs born to overnourished dams were largely delivered preterm, birth weight was additionally adjusted to a standard 146 days gestation using a formula derived from previously described serial necropsy studies in late gestation (Wallace et al. 2008): adjusted birth weight=weight at birth/1.01305 per day of gestation.

\section{Results}

\section{Pregnancy outcome and size at birth}

Lambs were spontaneously delivered between days 137 and 146 of gestation, and average gestation length was 3-4 days shorter in the overnourished group as expected (Table 1). Relative to optimally nourished controls, overfeeding was also associated with a major restriction in placental growth as reflected by $44 \%$ lower fetal placental weight and $71 \%$ lower total fetal cotyledon weight. A higher birthweight:cotyledon weight ratio implies enhanced nutrient transport in these restricted pregnancies but nevertheless fetal growth and hence 


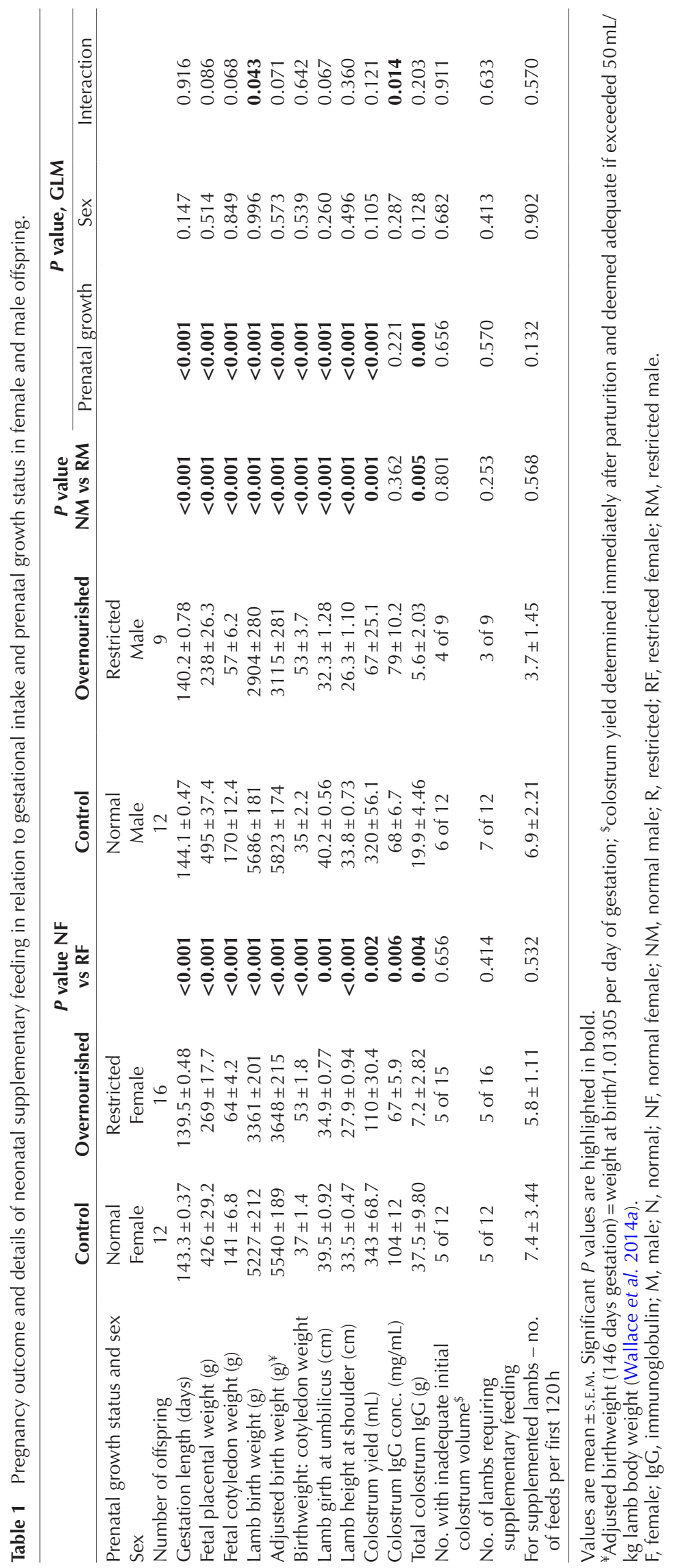




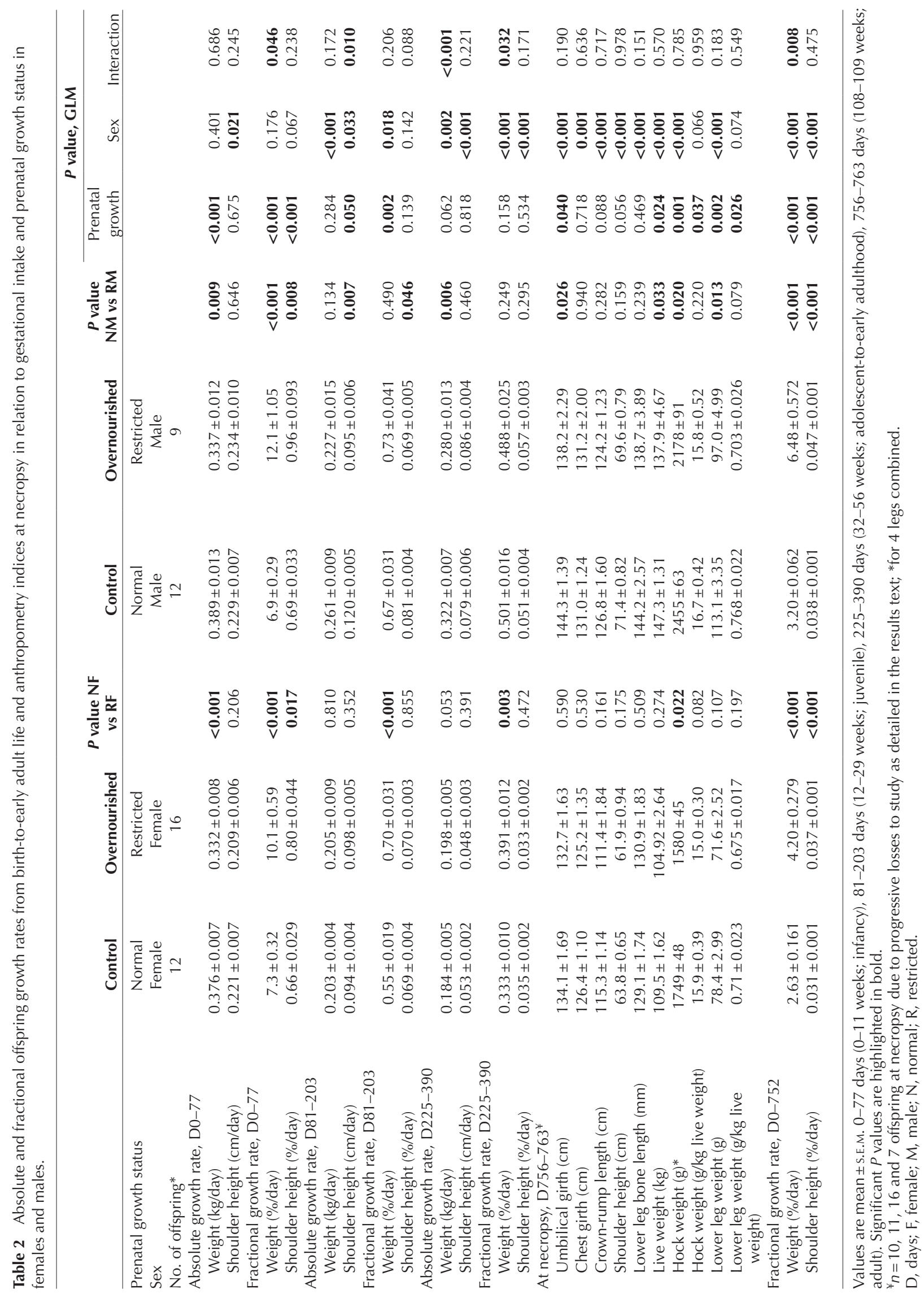


size at birth were constrained. The differential in average birthweight between growth-restricted and normal lambs was largely preserved even after adjusting all individual birthweights to a standard 146-day gestation (41 vs $39 \%$ respectively). Seven of the growth-restricted lambs weighed $<2500 \mathrm{~g}$ (range 1740-2310 g). Fetal cotyledon weight and birthweight were correlated in both normal $(r=0.590, \quad n=24, \quad P=0.002)$ and growth-restricted $(r=0.843, n=25, P<0.001)$ pregnancies. Colostrum yield immediately after parturition was variable but markedly lower overall in overnourished vs control dams. None of the aforementioned pregnancy outcomes were influenced by the sex of the lamb. Colostrum IgG concentration was independent of maternal nutrition in male groups and was greater in normal than in growthrestricted female groups. Irrespectively, the greater yield in the control groups meant that their total IgG content was markedly higher in both sexes. There was no impact of maternal nutrition/prenatal growth status on the number of ewes failing to meet the minimum requirement (50 $\mathrm{mL}$ colostrum $/ \mathrm{kg}$ birthweight) or the requirement for and frequency of colostrum/milk supplementation in the neonatal period in either sex (Table 1).

\section{Offspring growth and body composition by DEXA}

Five offspring did not complete the study. A normal female and the smallest birthweight male failed to continuously thrive adequately and were killed on welfare grounds at $\sim 41$ and 68 weeks of age respectively. A growth-restricted male and a normal female died suddenly at $\sim 47$ and 91 weeks of age respectively, and all veterinary investigations including a full post-mortem failed to identify the cause of death. The fifth animal was a normal male who suffered an accidental injury and death at 72 weeks of age. Data were analysed with and without these animals, but this did not significantly impact differences between groups. Growth to early adult life and anthropometry at necropsy are detailed in Table 2.

\section{Infancy period: birth to weaning}

During the 11-week suckling phase AGR for weight was lower in prenatally growth-restricted compared with normal birthweight offspring $(P<0.001$ and $P=0.009$ in females and males respectively), while AGR for height was higher overall $(P=0.021)$ in males than in females. In contrast, when expressed on a fractional basis relative to birthweight, the overall FGR for weight and height were greater $(P$ values ranging from 0.017 to $<0.001$ ) in growth-restricted groups of both sexes, and this was also evident from the CFGR data throughout the suckling phase (Fig. 1). At each of the weekly time points, CFGR for weight and height was greater in prenatally growthrestricted vs normal birthweight lambs with the most pronounced differences evident soon after birth.
The cFGR for weight and height were also lower in females than in males but on balance, the effect of prenatal growth category was more pronounced than that of sex at this stage. Accordingly, the inverse relationships between birthweight and overall FGR for weight and height during the suckling phase were strong $(r=-0.902$ and $-0.713, n=49, P<0.001)$. DEXA measurement of body composition immediately prior to weaning revealed that prenatally growth-restricted lambs of both sexes had a higher fat to lean mass ratio compared with normal lambs (females, $P=0.025$; males, $P<0.001$, Fig. 2A). Irrespective of prenatal growth category females were markedly fatter than males at this early stage $(P<0.001)$ and an inverse relationship between birthweight and percentage body fat was evident in both sexes (females, $r=-0.436, P=0.026$, and males, $r=-0.567, P=0.014$, Fig. 2B). In contrast prenatally growth-restricted lambs had lower BMD, particularly in the female comparison $(P=0.019)$, and the relationship between birthweight and BMD was positive in both sexes (females, $r=0.552, P=0.002$ and males, $r=0.473, P=0.030$, Fig. $2 \mathrm{D}$ and $\mathrm{E})$.

Juvenile phase: weaning to 29 weeks

Absolute daily growth rates (weight and height) in the juvenile period from weaning to 29 weeks of age were greatest in normal males (Table 2). Growth in all groups slowed appreciably after weaning but cFGR for weight and height at all stages remained higher in the prenatally growth-restricted vs normal groups of both sexes and was lower in females than in males (Fig. 1). Body composition at the DEXA measurement taken soonest after the end of the juvenile period, at 41 weeks of age, revealed an effect of prenatal growth status on BMD in both sexes (restricted $<$ normal, females $P=0.001$; males $P=0.004$, Fig. 2D) and an emerging influence of sex irrespective of growth category (female $<$ male, $P<0.001)$ ). Bone mineral accrual between 11 and 41 weeks of age was greatest in normal males in line with their higher AGR but all offspring displayed a marked increase in BMD during this period (Fig. 3, $P<0.001$ for all within-group comparisons). The percentage body fat did not change between weaning and 41 weeks of age in growth-restricted males (21.3 vs $20.4 \%$ ) but increased in all other groups (Fig. 3, $P<0.05$ to $<0.001$ for within group comparisons). At 41 weeks, the fat-to-lean mass ratio was independent of prenatal growth category in both sexes and irrespective of growth category females remained proportionately fatter than males $(P<0.001$, Fig. 3A). At this stage, the average differential in body fat between sexes was $10.8 \%$.

\section{Adolescence to early adulthood}

In the period from 32 to 56 weeks of age, spanning adolescence to early adulthood, male offspring had greater absolute and FGR than females (weight and 

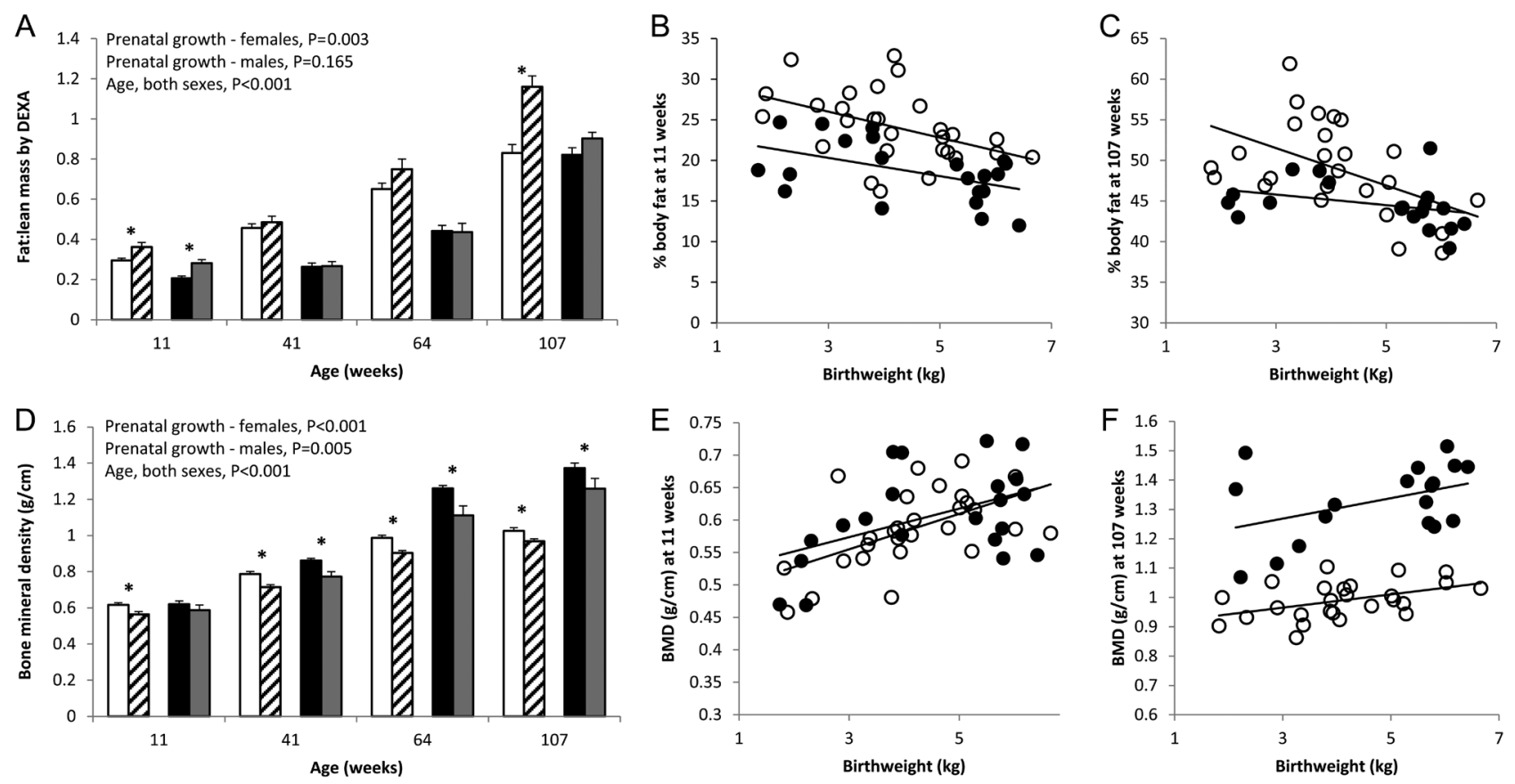

Figure 2 Effect of prenatal growth on (A) fat: lean mass and (D) BMD measured by DEXA at 11, 41, 64 and 107 weeks of age in normal birthweight females (open bars) and growth-restricted females (hatched bars), and in normal birthweight males (solid-black bars) and growthrestricted males (grey bars). Values are mean \pm S.E.M. $P$ values refer to repeated measures ANOVA carried out separately for females and males, and * indicates an effect of prenatal growth at a specific age following post hoc comparisons of all ages, $P<0.05$. For $(A)$ there was a prenatal growth status $\times$ age interaction in females $(P<0.001)$. Relationship between birthweight and \% body fat $(\mathrm{B}$ and $\mathrm{C})$, and birthweight and $\mathrm{BMD}(\mathrm{E}$ and $\mathrm{F}$ ) at 11 and 107 weeks of age in females (open circles) and males (closed circles). See text for correlation coefficients. BMD, bone mineral density; DEXA, dual-energy X-ray absorptiometry.

height), with absolute weight gain once more being higher $(P=0.006)$ in normal vs restricted males. During this period, overall FGR for weight was greater $(P=0.003)$ in prenatally growth-restricted compared with normal females (Table 2). BMD increased between 41 and 64 weeks of age in all offspring $(P<0.001$ for within group comparisons) and the accrual rate was almost two-fold higher in males than in females during this period again in keeping with their faster AGR. At 64 weeks of age, the DEXA scan confirmed a persistent effect of prenatal growth status (restricted $<$ normal, females $P<0.001$; males $P=0.005$ ) and sex (female $<$ male, $P<0.001$ ) on BMD (Fig. 2D). Percentage body fat increased between 41 and 64 weeks in all groups (Fig. 3). At 64 weeks, the ratio of fat to lean mass remained independent of prenatal growth category in both sexes and average body fat in females irrespective of prenatal growth status was $10.7 \%$ greater than in males $(P<0.001)$.

\section{Early adulthood to necropsy at mid-adulthood}

Offspring continued to grow during the second year of life albeit at a slower rate. During this time, absolute and fractional changes in weight and height were independent of prenatal growth status and higher in males than in females (data not shown). Accordingly, males were heavier, longer (crown-rump length), wider (girth at umbilicus and chest) and taller (shoulder height and lower leg bone length) than females at necropsy $(P=0.001,108 / 109$ weeks of age, Table 2). FGR for weight from birth to necropsy was higher in prenatally restricted vs normal groups of both sexes $(P<0.001)$ and was inversely correlated with birthweight $(r=-0.818$, $P<0.001$ ). Nevertheless, absolute catch-up was not completely achieved and prenatally restricted offspring remained lighter at necropsy, with the most pronounced effect evident in males. Similarly with respect to height, FGR from birth to necropsy was greater in prenatally restricted vs normal groups of both sexes $(P<0.001)$ and was inversely correlated with birthweight $(r=-0.826$ and -0.896 in females and males respectively, $P<0.001$ ). Although shoulder height at necropsy was slightly lower in prenatally growth-restricted compared with normal offspring $(P=0.056)$, this failed to reach significance within either sex separately. Nevertheless, the lower absolute and relative weights of the hocks and lower leg are commensurate with the prenatally restricted offspring having modestly reduced stature at necropsy.

DEXA measurement of body composition prior to necropsy revealed that the effect of prenatal growth status on BMD persisted in both sexes to the end of the study (Fig. 2D). The positive relationship between birthweight and BMD was still evident in the population as a whole $(r=0.392, P=0.009)$ and in females only $(r=0.452$, 

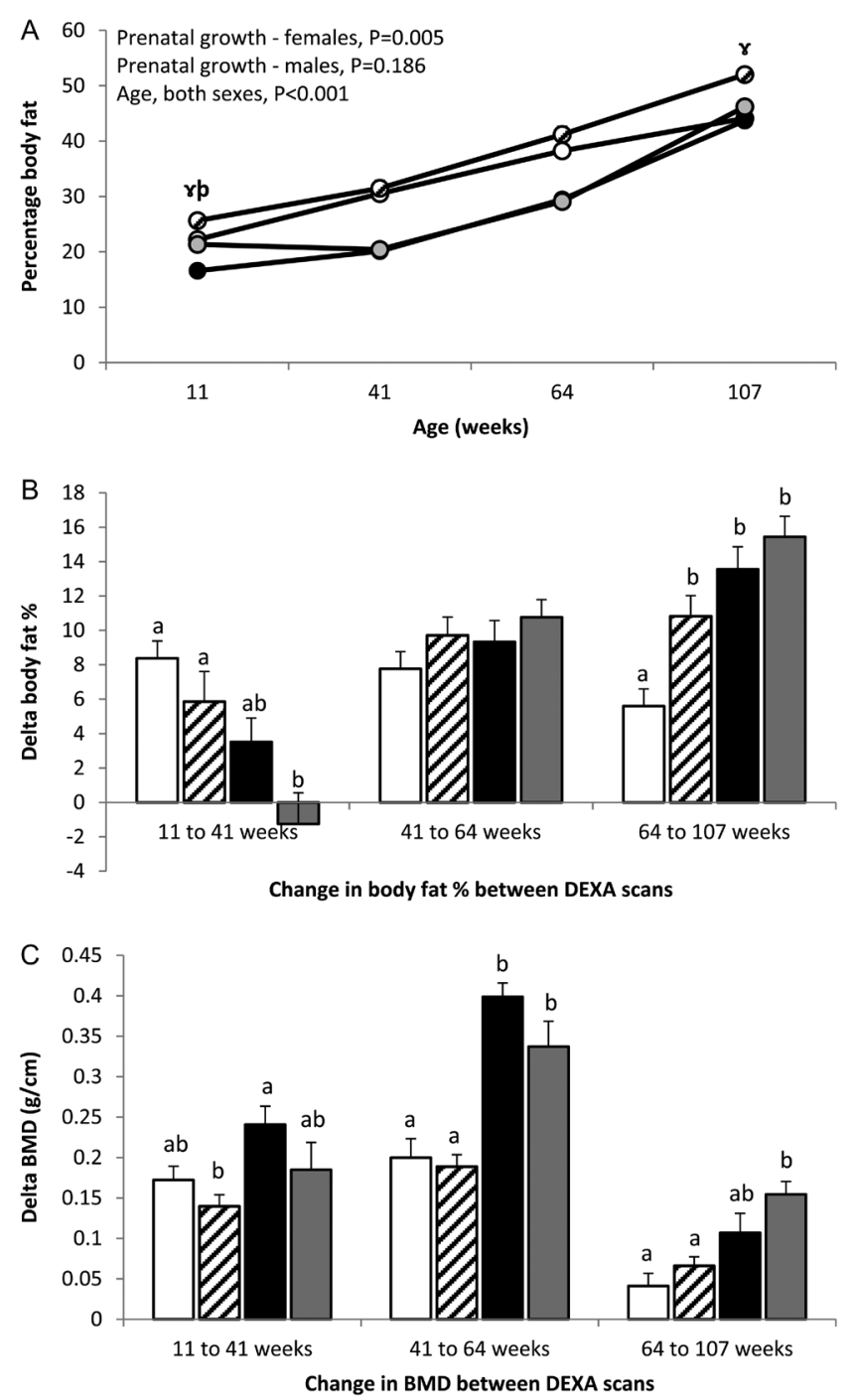

Figure 3 Effect of prenatal growth on (A) percentage body fat measured by DEXA at 11, 41, 64 and 107 weeks of age and the change in (B) body fat and (C) BMD between these ages in normal birthweight females (open bars) and growth-restricted females (hatched bars), and in normal birthweight males (solid black bars) and growth-restricted males (grey bars). Values are mean \pm S.E.M. For (A) $P$ values refer to repeated measures ANOVA carried out separately for females and males, while $r$ and $p$ indicate an effect of prenatal growth at a specific age following post hoc comparisons of all ages for females and males respectively $P<0.05$. For (A) prenatal growth status $\times$ age interaction, $P=0.010$ in females and $P=0.066$ in males. For (B) and (C) where superscript letters above columns differ within periods, $P<0.05$. BMD, bone mineral density; DEXA, dual-energy $\mathrm{X}$-ray absorptiometry.

$n=26, P=0.020)$ but failed to reach formal statistical significance in males $(r=0.425, n=18, P=0.079)$. The change in BMD between 64 and 107 weeks was very small in normal females $(P>0.1)$ commensurate with peak bone mass having already been achieved (Fig. 3C). In contrast, growth-restricted females continued to accrue a small amount of bone mineral during the
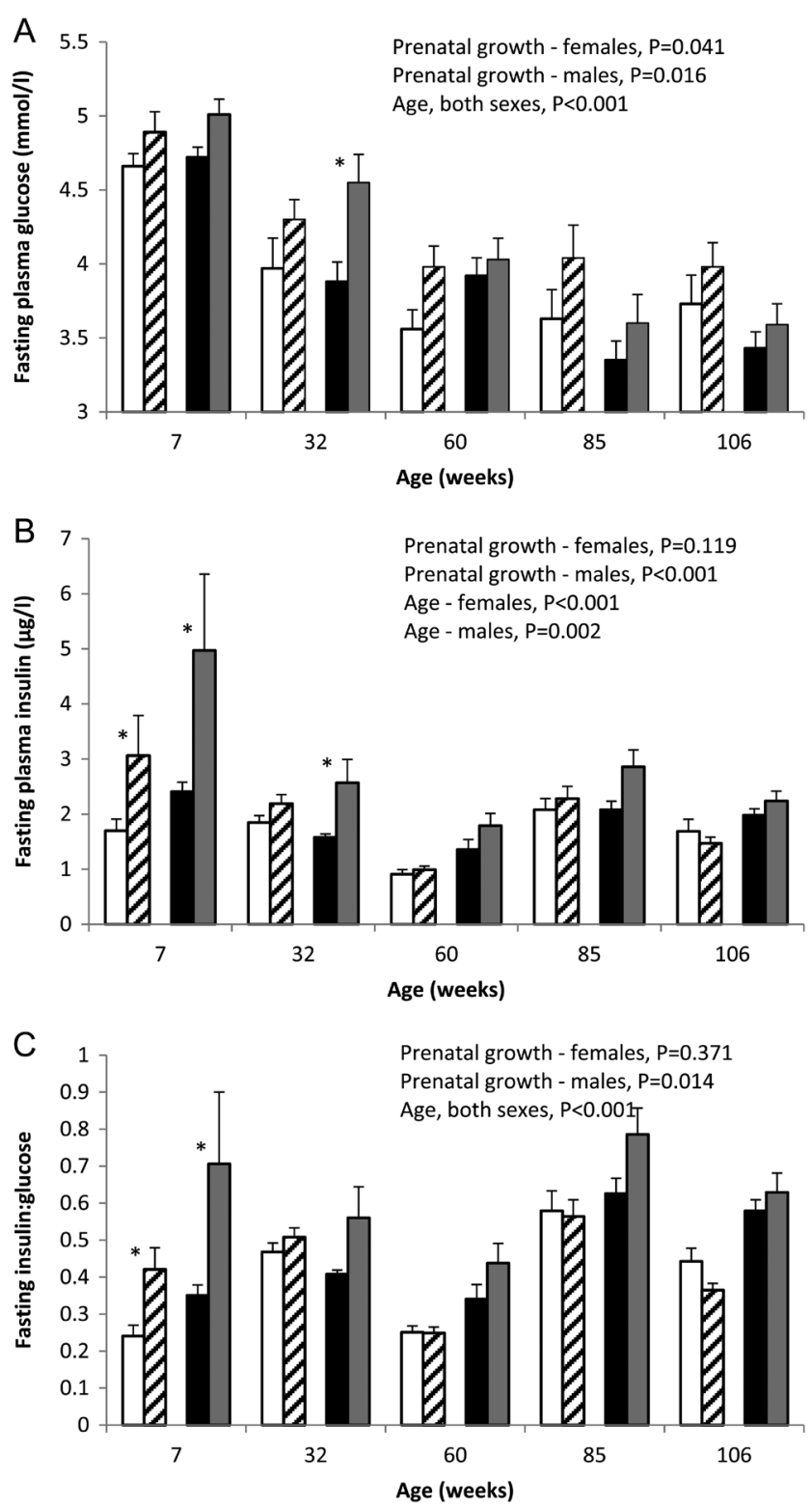

Figure 4 Effect of prenatal growth on fasting plasma (A) glucose and (B) insulin concentrations and (C) insulin: glucose ratio at 7, 32, 60, 85 and 106 weeks of age in normal birthweight females (open bars) and growth-restricted females (hatched bars), and in normal birthweight males (solid black bars) and growth-restricted males (grey bars). $P$ values refer to repeated measures ANOVA carried out separately for females and males. * indicates an effect of prenatal growth at a specific age following post hoc comparisons of all ages, $P<0.05$. Lambs were fasted for $3 \mathrm{~h}$ at 7 weeks of age (lactation phase) and overnight at all stages thereafter.

second year of life $(P<0.01)$. The change in BMD during this period was higher but more variable in males $(P=0.005)$ and the within-group comparison reached statistical significance in normal males $(P<0.01)$ only. Percentage body fat increased between 64 and 107 weeks in all groups but to a lower extent in normal females than in all other groups (Fig. 3B). At necropsy 


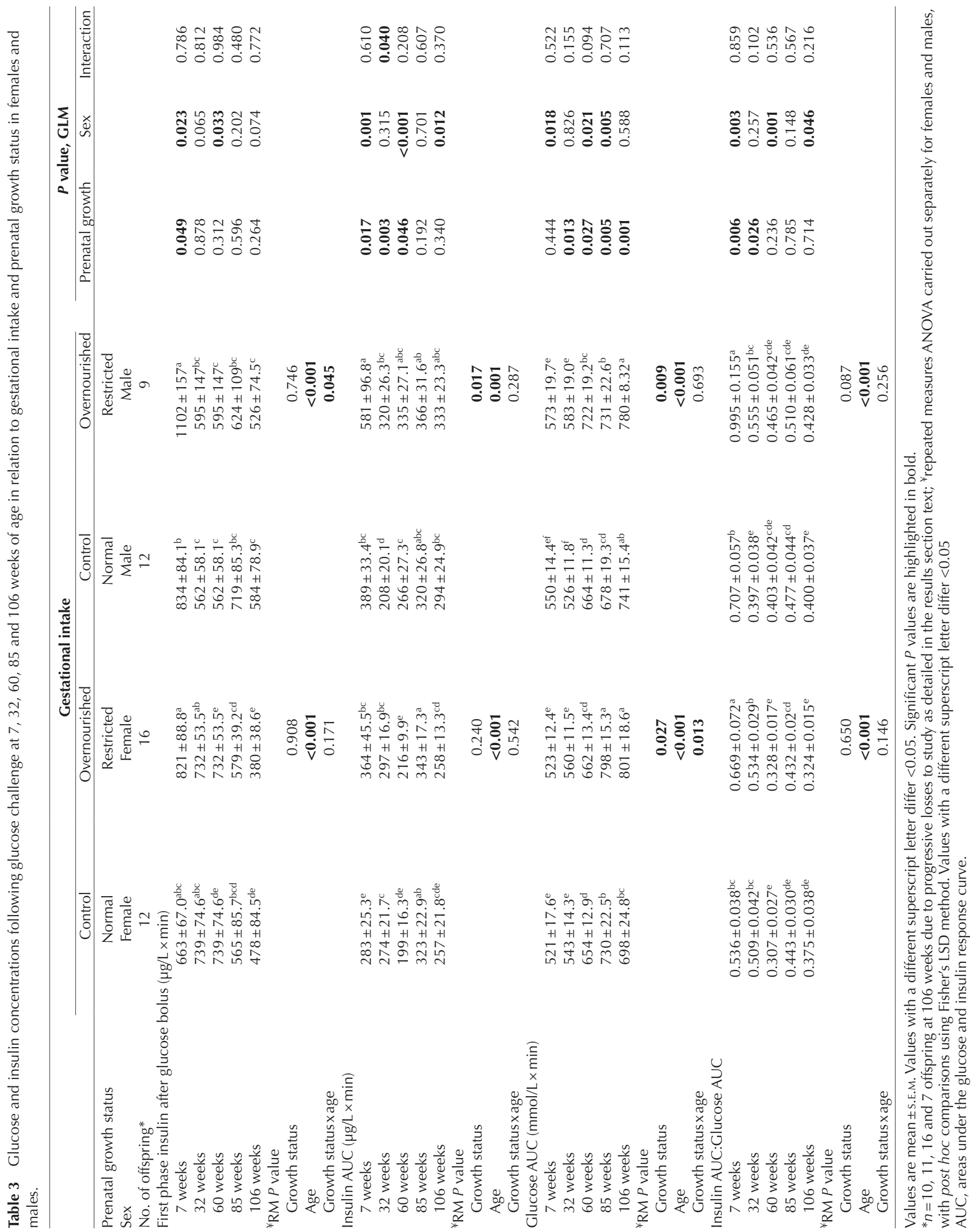


the fat: lean mass ratio and percentage body fat were greater in growth-restricted than in normal birthweight females but a similar trend in males was not statistically significant by either the repeated measures or GLM approach (Figs 2A and 3A). Thus, an inverse association between birthweight and body fat at 107 weeks of age was observed in the population as a whole $(r=-0.462$, $P=0.002)$ and in females only $(r=-0.504, P=0.009)$ but not in males ( $r=-0.335, P=0.175$, Fig. 2C).

\section{Glucose handling throughout the life course}

\section{Fasting glucose and insulin concentrations}

The repeated-measures analysis revealed an influence of prenatal growth category on fasting glucose concentrations (normal< $<$ growth- restricted) across the life course in both female $(P=0.041)$ and male $(P=0.016)$ offspring (Fig. 4). The most pronounced difference in glucose concentrations was evident in males at 32 weeks of age. Relative to normal birthweight males, those that were prenatally growth- restricted also had higher fasting insulin concentrations $(P<0.001)$ and a greater fasting insulin:glucose ratio $(P=0.014)$, across the life course: in this instance, the most pronounced difference was evident at 7 and 32 weeks of age. In contrast, fasting insulin and the insulin:glucose ratio were largely unperturbed in the female groups, other than at 7 weeks of age when both parameters were higher $(P<0.05)$ in the growth-restricted females.
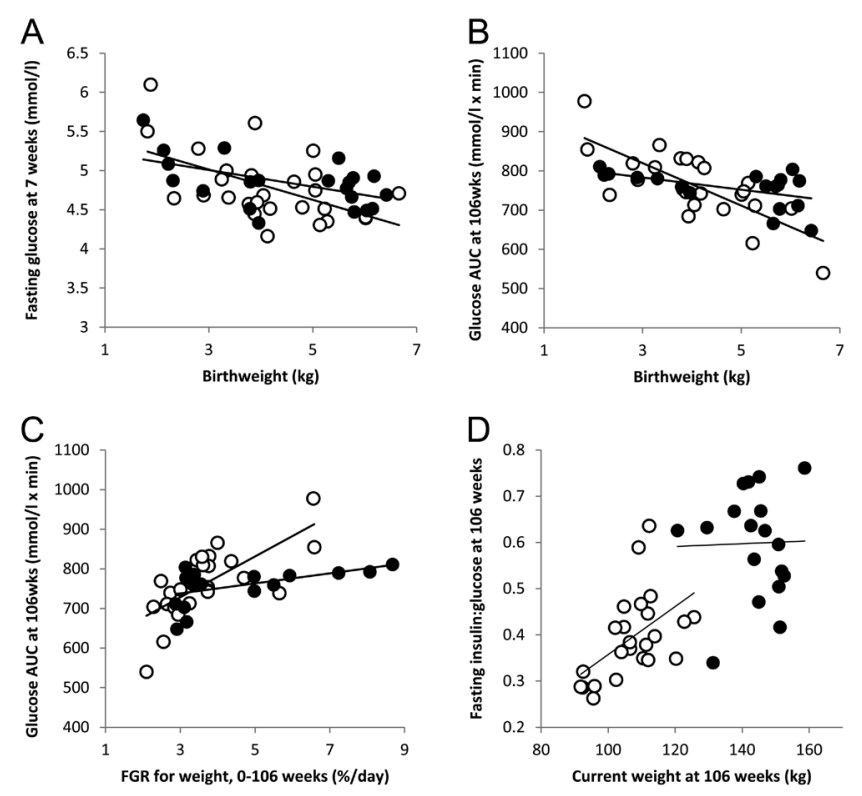

Figure 5 Relationship between (A) birthweight and fasting glucose concentrations at 7 weeks of age (infancy), (B) birthweight and glucose AUC at 106 weeks of age (mid-adulthood), (C) FGR for weight between birth and 106 weeks of age and glucose AUC at 106 weeks, and (D) current weight and the fasting insulin: glucose ratio at 106 weeks of age. See text for correlation coefficients. AUC, area under the curve; FGR, fractional growth rate.
The GLM analysis further revealed that close to the study end, females (irrespective of prenatal growth status) had modestly higher fasting glucose concentrations than males $(P=0.047)$, while males had higher fasting insulin and a greater insulin:glucose ratio (an index of relative insulin secretion) than females $(P=0.002$ and $P<0.001$ respectively).

Birthweight was negatively associated with fasting glucose concentrations at 7 weeks of age (infancy) in the population overall $(r=-0.501, n=49, P<0.001)$ and in males $(r=-0.532, n=21, P=0.013)$ and females $(r=-0.540, n=28, P=0.004)$ separately (Fig. 5A). The strength of this association was attenuated thereafter and persisted across the life course at a study population level (at 106 weeks, $r=-0.375, n=44, P=0.014$ ); this was largely due to the relationship in female offspring, which approached significance $(r=-0.381$, $P=0.066$ ). At 7 weeks of age, birthweight was also negatively associated with fasting insulin concentrations ( $r=-0.421, P=0.003$ for population as a whole, and $r=-0.422, P=0.057$ and $r=-0.514, P=0.006$ in males and females separately), but this relationship did not persist beyond the infancy period. By study end, there was a positive relationship between current body weight and both fasting insulin and the fasting insulin to glucose ratio in females only $(r=0.415, P=0.044$ and $r=0.520$, $P=0.009$ respectively vs $P>0.32$ in males, Fig. 5D).

\section{Glucose and insulin concentrations after metabolic challenge}

Summary glucose and insulin responses following glucose challenge in relation to prenatal growth category and for each sex (i.e. all four groups) are presented in Table 3, while the glucose and insulin profiles for growth-restricted vs normal female offspring are shown in Supplementary Fig. 1 (see section on supplementary data given at the end of this article). Intravenous administration of a glucose bolus induced a significant rise in plasma glucose followed immediately by a rise in insulin at all life stages studied. The repeated-measures analysis revealed an overall impact of prenatal growth status on glucose tolerance (area under the glucose response curve, glucose $A \cup C$ ) in females and males $(P=0.027$ and $P=0.009$ respectively). In females, there was also a significant growth status $\times$ age interaction, which reflected that the glucose AUC was largely independent of prenatal growth status at 7, 32 and 60 weeks but higher in the growth-restricted group at 85 and 106 weeks of age. In males, there was no interaction and the most pronounced difference in glucose AUC between the growth-restricted and normal groups was at 32, 60 and 85 weeks of age. The GLM analysis further reveals that by 106 weeks of age the greater glucose $A \cup C$ in the growth-restricted groups reflected a reduced rate of glucose clearance from 10 to $180 \mathrm{~min}$ after 
the glucose bolus, which was largely independent of offspring sex (Table 3 and Supplementary Fig. 1).

With regard to insulin sensitivity (area under the insulin response curve, insulin AUC) the repeatedmeasures analysis revealed that the first phase response, insulin AUC overall, as well as relative insulin secretion (insulin AUC: glucose AUC), all differed by age in both female and male offspring $(P<0.001)$. There was no overall impact of prenatal growth on postnatal insulin sensitivity or relative secretion in females across the entire life course but at 7 weeks of age, the overall insulin AUC and insulin AUC: glucose AUC were higher in the growth-restricted group $(P<0.05$, Table 3 and Supplementary Fig. 1). In male offspring, there was a modest prenatal growth effect on insulin AUC $(P=0.017)$ overall, and this primarily reflected a greater AUC in growth-restricted males at both 7 and 32 weeks of age. Growth-restricted males also had a higher first phase insulin response at 7 weeks and relative insulin secretion at both 7 and 32 weeks of age (Table 3).

The inverse association between birthweight and glucose AUC become significant at 32 weeks $(r=-0.451$, $P=0.001)$ and progressively stronger until 106 weeks of age for the study population as a whole $(r=-0.612$, $P<0.001)$ and for males and females separately $(r=-0.526, \quad P=0.025$ and $r=-0.749, \quad P<0.001$, Fig. 5B). A similarly strong but positive relationship was detected between FGR for weight throughout the study (birth to 106 weeks) and glucose AUC at 106 weeks in the combined population $(r=0.525, P<0.001)$ and in males $(r=0.522, P=0.020)$ and females $(r=0.705$, $P<0.001$ ) separately (Fig. 5C). Current weight at study end was unrelated to glucose tolerance $(P>0.34)$. In direct contrast, there was no relationship between either birthweight or FGR and insulin sensitivity at 106 weeks $(P>0.32)$. Current weight at study end was positively associated with both insulin $A \cup C$ and the insulin AUC:glucose AUC for the population as a whole ( $r=0.423, P=0.005$ and $r=0.413, P=0.007$ respectively) but not for the sexes separately $(P>0.1)$.

\section{Discussion}

The key features of pregnancy outcome previously demonstrated in our adolescent sheep model were replicated in the present study. Relative to optimally fed controls of equivalent age, the pregnancies of young dams that were overnourished throughout gestation were characterised by a major reduction in placental growth, and premature delivery of growth-restricted lambs. The differential in average birthweight in growth-restricted vs control (normal) lambs, even after mathematical correction for gestation length, was 39\% and is commensurate with the degree of perturbation reported previously during late pregnancy (range 28-37\%, Wallace et al. 2000, 2003, 2007, Matsuzaki et al. 2006), and following spontaneous delivery at term (range 22-38\%, Wallace et al. 1996, 1999, 2010, 2012). Notably, in the present study, $28 \%$ of lambs born to overnourished adolescent dams were extremely small $(<2500 \mathrm{~g})$ and were born at an average gestation of 138 days. Sheep tolerate prematurity poorly and as colostrum supply was particularly attenuated in these particular dams (range $0-72 \mathrm{~mL}$ ), our proactive regimen of intensive care, including supplementary feeding for up to 5 days, was essential to ensure the most severely growth-restricted lambs survived the rigours of the neonatal period and were able to enter the postnatal part of the study. These small premature lambs were undoubtedly the most vulnerable to starvation and infection at birth, but overall, there was no difference between restricted and normal groups in the proportion of animals requiring supplementary feeds or the number of feeds needed to ensure neonatal weight gain. This in part reflects the higher absolute nutrient requirement in the heavier offspring born to control adolescent mothers. We believe the present study represents the most comprehensive longitudinal assessment of the impact of major prenatal growth restriction on postnatal growth, glucose handling and body composition across the life course in both sexes documented to date. Inevitably, there were a number of dropouts, but nevertheless, 92 and $87.5 \%$ of growthrestricted and normal offspring respectively, completed the 2-year study.

\section{Effect of prenatal growth status on postnatal growth and body composition}

Prenatally growth-restricted lambs of both sexes exhibited higher growth rates relative to their initial size for weight and height, both in terms of overall and current FGR throughout the period spanning birth to adolescence. As expected, growth was particularly rapid during the lactation/suckling period when the normal inverse relationship between birthweight and fractional growth is known to be particularly strong (Wallace et al. 2010, 2012). Nevertheless growth-restricted lambs born preterm remained $18 \%$ lighter than normal birthweight lambs at 11 weeks of age when DEXA assessment of body composition revealed a higher fat:lean mass and a strong inverse relationship between birthweight and body fat percentage in both sexes. This small fat phenotype at the point of weaning is in line with prior observations in late pregnancy where restricted fetuses from overnourished dams had higher fetal weightspecific perirenal fat mass and carcass fat (Matsuzaki et al. 2006). This increase in relative adiposity in late fetal life may arise as a consequence of exposure to higher maternal and thereby fetal glucose early in gestation in the overnourished dams (Redmer et al. 2009), at a time before placental growth and hence fetal glucose supply is constrained. Such exposure to high 
glucose may influence the earliest stages of adipose tissue development. Indirect but convincing support for this assertion comes from a recent study reporting that key genes that regulate adipose tissue development and function are active in mid-gestation (day 90) when they are sensitive to maternal undernutrition leading to reduced adiposity by late gestation (Wallace et al. 2015). Further support that increased offspring adiposity at weaning may in part reflect the different levels of maternal prenatal diet comes from a comparison of growth-restricted vs relatively normal weight lambs all born prematurely to overnourished adolescent dams and necropsied at 11 weeks of age (Wallace et al. 2014a). In this instance, body composition (carcass fat and perirenal fat mass) was completely independent of prenatal growth category in spite of high FGR in the restricted lambs similar to those reported herein. In contrast, in the premating carunclectomy model where maternal nutrition status during pregnancy is also assumed to be equivalent, and gestation length is largely unperturbed, singleton lambs with a $25 \%$ decrease in birthweight relative to controls show rapid and complete catch-up in terms of weight by 6 weeks of age and are fatter at this early stage (De Blasio et al. 2007a). Indeed when the perturbation in gestation length and birthweight in the overnourished adolescent model is less extreme than that reported here, i.e. a $22 \%$ vs $40 \%$ decrease in actual weight at birth, complete catch-up in terms of weight is observed by weaning at 11 weeks of age (Wallace et al. $2010,2012)$. Thus, the ability of growth-restricted lambs to achieve complete catch-up growth and/or display altered body composition in this early postnatal period is likely to be a feature of the degree of prematurity and birthweight suppression between comparator groups as well as differences in maternal nutrition, age, parity, genotype and offspring appetite.

In the present study, growth rates decreased after weaning and even although current FGR remained higher in the prenatally growth-restricted groups through to adolescence, offspring adiposity was independent of prenatal growth status at both the adolescent and early adult stage DEXA assessments (41 and 64 weeks). Notably growth-restricted males failed to accrue any additional body fat between weaning and adolescence suggesting that lean tissue and skeletal growth were the main priority for these animals during this period. Offspring growth was assumed to be complete by midadult life: nevertheless, the growth-restricted offspring of both sexes had still not achieved their genetic potential and overall had modestly lower weight and stature at study end. Moreover, growth-restricted offspring, primarily the females, were once again fatter at this time point and the inverse relationship between birthweight and body fat percentage was apparent at the study population level. There are few comparable studies in sheep of a similar duration that document adult size and body composition after prenatal growth restriction. An early report in a small group of females, growth-restricted following twinning and placental embolism, showed that in spite of a $38 \%$ reduction in birthweight, body weight was restored by 8 weeks of age and remained equivalent at 2.5 years: nonetheless, these females had greater abdominal fat mass at necropsy (Louey et al. 2005). Studies involving the premating carunclectomy model and a 25-29\% decrease in birthweight also reported early postnatal growth compensation but no impact on weight, height or adiposity (by DEXA) at 1 or 1.5 years (Owens et al. 2007, Liu et al. 2015). The end points of the latter studies are similar to the 41 - and 64-week assessments herein when body fat was also not different between restricted and control groups of either sex and serve to illustrate the potential difficulty of using a single body composition measurement to detect and describe a potentially programmed phenotype. The measurements at study end in the present study concur with the higher body fat content (by DEXA) in young adult males with birthweights less than the 10th centile for gestational age (Rasmussen et al. 2005).

We believe the present study is the first to serially document BMD in relation to prenatal growth restriction in sheep. The positive relationship between birthweight and BMD at the weaning stage was not unexpected: $80 \%$ of a newborn human baby's bone mass is acquired during the exponential fetal growth phase in the final trimester (Trotter \& Hixon 1974) and hence when prenatal conceptus growth is perturbed to the level achieved herein, it is highly probable that skeletal development will also be disturbed. In support, studies in humans demonstrate that placental volume measured by ultrasound at 19-week gestation (a proxy for fetal nutrient supply) predicts neonatal bone mineral content and density (Holroyd et al. 2012) and both estimated fetal weight at 30-week gestation and birthweight are positively associated with BMD at 6 months of age (Ay et al. 2011). In the latter study, infants who displayed weight catch-up, particularly between 6 weeks and 6 months of age had a reduced probability of low BMD at 6 months of age, but in the present study, BMD was attenuated in prenatally growth-restricted offspring at all stages measured irrespective of high FGR in the first year of life. While many studies in humans have linked birthweight to bone mass in childhood, adolescent or adult life, there is a paucity of information spanning the entire life course in the same individuals (MartinezMesa et al. 2013). The present animal study is free from many of the potential lifestyle confounders of bone mass in human studies e.g. smoking and alcohol, and demonstrates unequivocally that major prenatal growth restriction has a lifelong impact on bone density from the suckling through to the mid-adult stage, by which time peak bone mass has been achieved. Similarly, a recent human study of preterm and small-for-gestational-age (SGA) vs appropriate-for-gestational age individuals at $\sim 10$ years of age, and 27 years later, reveals that the 
modest reduction in adult height in the SGA group was due to a deficit in bone mineral accrual (Buttazzoni et al. 2016). Together, these studies support the concept of bone programming as a consequence of impaired fetal nutrient supply.

\section{Effect of sex on postnatal growth and body composition}

Although there were no sex-specific differences in gross lamb anthropometry at birth within the growthrestricted or control groups, postnatal growth and body composition thereafter were markedly dissimilar. Skeletal growth, as evidenced by changes in shoulder height, and bone mass, as evidenced by BMD, were greater in males vs females by weaning at 11 weeks of age and remained higher thereafter. After weaning, absolute weight gain was also greater in males, all of which contributed to males being considerably larger at necropsy in adult life. In contrast, females were fatter than males at 11 weeks of age, and this difference was maintained throughout the life course. Similarly striking sex-specific differences in indices of early postnatal body composition namely greater visceral fat mass, leptin gene expression, adipocyte size and percentage carcass fat in females, and greater carcass weights, hepatic IGF1 DNA methylation, mRNA expression and plasma IGF-1 concentrations in males, all independent of birthweight, have been measured following necropsy at 11 weeks of age (Wallace et al. 2014a,b, Carr et al. 2015). Moreover, these differences in body composition were mirrored by sexual dimorphism in the hypothalamic expression of anorexigenic and orexigenic genes $(n=5)$ involved in appetite control and body weight regulation (Adam et al. 2013). Together, these prior and current studies suggest that females partition more nutrients into fat than into lean tissue from early in postnatal life. Indeed, we have evidence that this sex-specific difference in nutrient partitioning arises in utero as body weightspecific perirenal fat mass in normally growing lategestation females is higher than that in males $(5.6 \pm 0.3$ vs. $3.7 \pm 0.4 \mathrm{~g} / \mathrm{kg}$ fetus respectively, $n=24, P=0.001$; J $M$ Wallace, unpublished data). In a separate unrelated study (Wallace et al. 2015), leptin and lipoprotein lipase gene expression in fetal perirenal fat was greater in females than in males: both these observations in fetal life support a temporal sex-specific difference in the earliest stages of adipose tissue development and the results of the present study suggest that this is likely to be lifelong. Clearly, offspring sex is an important consideration and it is of concern that many studies aiming to link different prenatal growth trajectories with body composition in later life have failed to stratify their data by sex or have been unable to study both sexes due to uneven or low numbers in comparison groups (Louey et al. 2005, Ford et al. 2007, Martinez-Mesa et al. 2013, Ong et al. 2015, Castanys-Muñoz et al. 2017).

\section{Effect of prenatal growth and sex on glucose metabolism}

In the present study, fasting plasma glucose and insulin concentrations were higher in growth-restricted offspring during the suckling period and into adolescent life. This represents a reversal of the pattern seen in late pregnancy when identically treated fetuses were hypoglycaemic and hypoinsulinaemic relative to normally growing controls (Wallace et al. 2000, 2002). Nevertheless, in utero, these growth-restricted fetuses show normal body-weight-specific metabolic responses to short-term acute experimental increases in plasma insulin and glucose (during hyperinsulinaemic-euglycaemic and hyperglycaemic-euinsulinaemic clamps respectively) indicating maintained mechanisms of insulin action and glucose uptake/utilisation capacity (Wallace et al. 2007). These adaptive mechanisms to preserve essential metabolic functions, and thereby cope with placental constraint of fetal nutrient supply in utero, are likely to persist into postnatal life where nutrient supply is no longer limiting. Indeed, in the present study, glucosestimulated insulin secretion following a standardized intravenous glucose bolus, and the insulin AUC-toglucose $A \cup C$ ratio were elevated in prenatally growthrestricted compared with normal offspring at 7 and 32 weeks of age. This enhanced insulin sensitivity apparent to varying degrees in growth-restricted offspring of both sexes is commensurate with their higher FGR during both the suckling and adolescent stages and the transiently higher adiposity measured at weaning. A similar increase in first phase insulin secretion during a rigorous hyperglycemic clamp was recently measured in eight-day-old lambs following hyperthermia-induced foeto-placental growth restriction (23\% lighter at birth, sex not specified, Camacho et al. 2017). By contrast, in the premating carunclectomy model, insulin secretion following a standard GTT, identical to that used herein, was attenuated at 5 weeks of age (De Blasio et al. 2007b). Together, these animal studies reflect the clinical situation, namely an inconsistent association between prenatal growth restriction and glucoseinsulin regulation in infancy (reviewed by Green et al. 2010, Gatford \& Simmons 2013). This may in part reflect differences in the timing, causes and extent of fetal growth restriction, as well as in the timing and mode of the postnatal assessment. In the adolescent model, placental mass is not perturbed until the final third of gestation and hence fetal growth per se is not constrained until after one of the main periods of pancreas development (Green et al. 2010). While this does not preclude a $\beta$-cell defect in early postnatal life, it is arguably less likely than in the hyperthermia and carunclectomy models where placental growth restriction is relatively early onset and hence fetuses are exposed to a poor nutrient supply for a longer period in utero. Indeed, early defects in $\beta$-cell mass and glucose- 
stimulated insulin concentrations were measured in the hyperthermia model before a discernible reduction in fetal weight at 0.7 of gestation (Limesand et al. 2013).

Herein, growth-restricted offspring were consistently characterised by increased fasting glucose and/or increased glucose AUC throughout the 2-year study. The negative relationship between birthweight and fasting glucose concentrations was strongest in early postnatal life but still detectable at study end, while the inverse association between birthweight and glucose tolerance became stronger with increasing age in both sexes. The former is consistent with the modest increase in fasting glucose previously reported in a less perturbed cohort of lambs born to overnourished compared with control-fed dams, and studied at 6 months of age (Wallace et al. 2012), and with the metabolic phenotype of growth-restricted vs normal weight lambs all born prematurely to overnourished adolescent dams (Wallace et al. 2014a). In the latter study, fasting glucose was elevated in the growth-restricted groups of both sexes at 7 weeks of age. In the present study, glucose intolerance after a body weight-specific glucose challenge was evident in prenatally growth-restricted male offspring at the juvenile stage (32 weeks of age) and beyond up to adulthood, while in growth-restricted females marked glucose intolerance did not emerge until early adulthood. In both sexes, this glucose intolerance preceded any change in body fat, which was manifest primarily in females at approximately 2 years of age. In comparison, placental and hence birthweight restriction by premating carunclectomy did not impact overall glucose tolerance compared with controls, but irrespective of treatment, birthweight per se was negatively correlated with glucose tolerance at 1 year of age in male, but not female, offspring (Owens et al. 2007). In a separate study in the same model, placental restriction was associated with increased glucose AUC in both males and females at 1.5 years of age, independent of any change in body composition (Liu et al. 2015). Low birthweight lambs from both the premating carunclectomy and overnourished adolescent models were fatter than controls in early postnatal life (De Blasio et al. 2007a, present study) but comparison between studies and stages suggests that an obese phenotype following severe prenatal growth restriction in these ovine models is transient in early life and may not reappear until mid-adult life, when the offspring have attained mature body size and experienced a prolonged period of glucose intolerance and the associated alteration in tissue glucose uptake. Of note in the present study is that the differential in glucose AUC in normal vs growth-restricted females at the final GTT was larger than in the corresponding male groups (13 vs $5 \%$ ), and it was the female comparison that also had the greatest differential in body fat at necropsy (7.9 vs $2.4 \%$ ). While this may well reflect a sexually dimorphic response to prenatal growth restriction, it could in part signify that females reached peak bone mass and adult size earlier in adult life (as indicated by BMD accrual) and were thereby more susceptible to the negative effects of persistent glucose intolerance earlier than in males and hence for a longer period before study end.

In conclusion, placentally mediated prenatal growth restriction resulting in early delivery and a major decrease in birthweight has negative consequences for glucose tolerance and body composition throughout the life course from weaning through to mid-adulthood. The ontogeny of these effects is influenced by sexually dimorphic differences in postnatal growth rate, fat deposition and bone mass accrual but irrespective prenatally growth-restricted offspring of both sexes have a less healthy phenotype in adult life.

\section{Supplementary data}

This is linked to the online version of the paper at https://doi.org/10.1530/REP-18-0048.

\section{Declaration of interest}

The authors declare there is no conflict of interest that could be perceived as prejudicing the impartiality of the research reported.

\section{Funding}

Funded by the Scottish Government's Rural and Environmental Science and Analytical Services Division (RESAS) including the Strategic Partnership for Animal Science.

\section{References}

Adam CL, Findlay PA, Aitken RP, Milne JS \& Wallace JM 2012 In vivo changes in central and peripheral insulin insensitivity in a large animal model of obesity. Endocrinology 153 3147-3157. (https://doi. org/10.1210/en.2012-1134)

Adam CL, Bake T, Findlay PA, Milne JS, Aitken RP \& Wallace JM 2013 Impact of birth weight and gender on early postnatal hypothalamic energy balance regulatory gene expression in the young lamb. International Journal of Developmental Neuroscience 31 608-615. (https://doi.org/10.1016/j.ijdevneu.2013.07.005)

AFRC Energy and Protein Requirements of Ruminants 1993 An Advisory Manual Prepared by the AFRC Technical Committee on Responses to Nutrients. Wallingford, UK: CAB International.

Araújo de Franca GV, Restrepo-Méndez MC, Loret de Mola C \& Victora CG 2014 Size at birth and abdominal adiposity in adults: a systematic review and meta-analysis. Obesity Reviews 15 77-91. (https://doi.org/10.1111/ obr.12109)

Ay L, Jaddoe VWV, Hofman A, Moll HA, Raat H, Steegers EAP \& HokkenKoelega ACS 2011 Foetal and postnatal growth and bone mass at 6 months: the Generation R study. Clinical Endocrinology 74 181-190. (https://doi.org/10.1111/j.1365-2265.2010.03918.x)

Barker DJ 2006 Adult consequences of fetal growth restriction. Clinical Obstetrics and Gynecology 49 270-283. (https://doi. org/10.1097/00003081-200606000-00009)

Belbasis L, Savvidou MD, Kanu C, Evangelou E \& Tzoulaki I 2016 Birthweight in relation to health and disease in later life: an umbrella review of systematic reviews and meta-analyses. BMC Medicine 14146. (https://doi.org/10.1186/s12916-016-0690-7) 
Bernstein IM, Horbar JD, Badger GJ, Ohisson A \& Golan A 2000 Morbidity and mortality among very-low-birth-weight neonates with intrauterine growth restriction. The Vermont Oxford Network. American Journal of Obstetrics and Gynecology 182 198-206. (https://doi.org/10.1016/ S0002-9378(00)70513-8)

Buttazzoni C, Rosengren B, Tveit M, Landin L, Nilsson JA \& Karlsson M 2016 Preterm children born small for gestational age are at risk of low adult bone mass. Calcified Tissue International 98 105-113. (https://doi. org/10.1007/s00223-015-0069-3)

Camacho LE, Chen X, Hay WW Jr \& Limesand SW 2017 Enhanced insulin secretion and insulin sensitivity in young lambs with placental insufficiency-induced intrauterine growth restriction. American Journal of Physiology: Regulatory Integrative and Comparative Physiology 313 R101-R109. (https://doi.org/10.1152/ajpregu.00068.2017)

Carr DJ, Aitken RP, Milne JS, David AL \& Wallace JM 2012 Fetoplacental biometry and umbilical artery Doppler velocimetry in the overnourished adolescent model of fetal growth restriction. American Journal of Obstetrics and Gynecology 207 141.e6-141.e15. (https://doi. org/10.1016/j.ajog.2012.05.008)

Carr DJ, Milne JS, Aitken RP, Adam CL \& Wallace JM 2015 Hepatic IGF1 DNA methylation is influenced by gender but not by IUGR in the young lamb. Journal of Developmental Origins of Health and Disease 6 558-572. (https://doi.org/10.1017/S2040174415001415)

Carr DJ, Wallace JM, Aitken RP, Milne JS, Martin JF, Zachary IC, Peebles DM \& David AL 2016 Peri- and postnatal effects of prenatal adenoviral VEGF gene therapy in growth-restricted sheep. Biology of Reproduction 94 142. (https://doi.org/10.1095/ biolreprod.115.133744)

Castanys-Muñoz E, Kennedy K, Castañeda-Gutiérrez E, Forsyth S, Godfrey KM, Koletzko B, Ocanne SE, Rueda R, Schoemaker M, van der Beek EM et al 2017 Systematic review indicates postnatal growth in term infants born small-for-gestationl-age being associated with later neurocognitive and metabolic outcomes. Acta Paediatrica 106 1230-1238. (https://doi.org/10.1111/apa.13868)

Caton J, Reed JJ, Aitken RP, Milne JS, Borowicz PP, Reynolds LP, Redmer DA \& Wallace JM 2009 Effects of maternal nutrition and stage of gestation on body weight, visceral organ mass, and indices of jejunal cellularity, proliferation, and vascularity in pregnant ewe lambs. Journal of Animal Science 87 222-235. (https://doi.org/10.2527/jas.2008-1043)

Crane JD, Yellin SA, Ong FJ, Singh NP, Konyer N, Noseworthy MD, Schmidt LA, Saigal S \& Morrison KM 2016 ELBW survivors in early adulthood have higher hepatic, pancreatic and subcutaneous fat. Scientific Reports 6 31560. (https://doi.org/10.1038/srep31560)

De Blasio MJ, Gatford KL, Robinson JS \& Owens JA 2007a Placental restriction of fetal growth reduces size at birth and alters postnatal growth, feeding activity, and adiposity in the young lamb. American Journal of Physiology: Regulatory Integrative and Comparative Physiology 292 R875-R886. (https://doi.org/10.1152/ajpregu.00430.2006)

De Blasio MJ, Gatford KL, McMillen C, Robinson JS \& Owens JA 2007 b Placental restriction of fetal growth increases insulin action, growth, and adiposity in the young lamb. Endocrinology 148 1350-1358. (https:// doi.org/10.1210/en.2006-0653)

Ford SP, Hess BW, Schwope MM, Nijland MJ, Gilbert JS, Vonnahme KA, Means WJ, Han H \& Nathanielsz PW 2007 Maternal undernutrition during early to mid-gestation in the ewe results in altered growth, adiposity, and glucose tolerance in male offspring. Journal of Animal Science 85 1285-1294. (https://doi.org/10.2527/jas.2005-624)

Gatford KL \& Simmons RA 2013 Prenatal programming of insulin secretion in intrauterine growth restriction. Clinical Obstetrics and Gynecology 56 520-528. (https://doi.org/10.1097/GRF.0b013e31829e5b29)

Ghidini A 1996 Idiopathic fetal growth restriction: a pathophysiologic approach. Obstetrical and Gynecological Survey 51 376-382. (https:// doi.org/10.1097/00006254-199606000-00023)

Gluckman PD \& Hanson MA 2008 Developmental and epigenetic pathways to obesity: an evolutionary-developmental perspective. International Journal of Obesity 32 (Supplement 7) S62-S71. (https://doi. org/10.1038/ijo.2008.240)

Green AS, Rozance PJ \& Limesand SW 2010 Consequences of a compromised intrauterine environment on islet function. Journal of Endocrinology 205 211-224. (https://doi.org/10.1677/JOE-09-0399)

Harder T, Rodekamp E, Schellong K, Dudenhausen JW \& Plagemann A 2007 Birth weight and subsequent risk of type 2 diabetes: a meta- analysis. American Journal of Epidemiology 165 849-857. (https://doi. org/10.1093/aje/kwk071)

Holroyd CR, Harvey NC, Crozier SR, Winder NR, Mahon PA, Ntami G, Godfrey KM, Inskip HM, Cooper C \& SWS Study Group 2012 Placental size at 19 weeks predicts offspring bone mass at birth: findings from the Southampton Women's Survey. Placenta 33 623-629. (https://doi. org/10.1016/j.placenta.2012.04.007)

Ibáñez L, Ong K, Dunger DB \& de Zegher F 2006 Early development of adiposity and insulin resistance after catch-up weight gain in smallfor-gestational-age children. Journal of Clinical Endocrinology and Metabolism 91 2153-2158. (https://doi.org/10.1210/jc.2005-2778)

Katanoda K, Noda M, Goto A, Mizunuma H, Lee JS \& Hayashi K 2017 Impact of birth weight on adult-onset diabetes mellitus in relation to current body mass index: the Japan Nurses' Health Study. Journal of Epidemiology 27 428-434. (https://doi.org/10.1016/j.je.2016.08.016)

Limesand SW, Rozance PJ, Macko AR, Anderson MJ, Kelly AC \& Hay WW Jr 2013 Reductions in insulin concentrations and $\beta$-cell mass precede growth restriction in sheep fetuses with placental insufficiency. American Journal of Physiology: Endocrinology and Metabolism 304 E516-E523. (https://doi.org/10.1152/ajpendo.00435.2012)

Liu H, Schultz CG, De Blasio MJ, Peura AM, Heinemann GK, Harryanto H, Hunter DS, Wooldridge AL, Kind KL, Giles LC et al. 2015 Effect of placental restriction and neonatal exendin-4 treatment on postnatal growth, adult body composition, and in vivo glucose metabolism in sheep. American Journal of Physiology: Endocrinology and Metabolism 309 E589-E600. (https://doi.org/10.1152/ajpendo.00487.2014)

Louey A, Cock ML \& Harding R 2005 Long term consequences of low birthweight on postnatal growth, adiposity and brain weight at maturity in sheep. Journal of Reproduction and Development 51 59-68. (https:// doi.org/10.1262/jrd.51.59)

MacRae JC, Bruce LA, Hovell FDB, Hart IC, Inkster J \& Atkinson T 1991 Influence of protein nutrition on the response of growing lambs to exogenous bovine growth hormone. Journal of Endocrinology 130 53-61. (https://doi.org/10.1677/joe.0.1300053)

Martinez-Mesa J, Restrepo-Méndez MC, González DA, Wehrmeister FC, Horta BL, Domingues MR \& Menezes AMB 2013 Life-course evidence of birth weight effects on bone mass: systematic review and metaanalysis. Osteoporosis International 24 7-18. (https://doi.org/10.1007/ s00198-012-2114-7)

Matsuzaki M, Milne JS, Aitken RP \& Wallace JM 2006 Overnourishing pregnant adolescent ewes preserves perirenal fat deposition in their growth-restricted fetuses. Reproduction, Fertility and Development 18 357-364. (https://doi.org/10.1071/RD05067)

Morrison JL 2008 Sheep models of intrauterine growth restriction: fetal adaptations and consequences Clinical and Experimental Pharmacology and Physiology 35 730-743. (https://doi.org/10.1111/j.14401681.2008.04975.x)

Ojha S \& Budge H 2012 Early origins of obesity and development. In Adipose Tissue Biology, pp 379-408. Ed ME Symonds. Berlin: Springer Science+Business Media.

Ong KK, Kennedy K, Castañeda-Gutiérrez E, Forsyth S, Godfrey KM, Koletzko B, Latulippe ME, Ozanne SE, Rueda R, Schoemaker M et al. 2015 Postnatal growth in preterm infants and later health outcomes: a systematic review. Acta Paediatrica 104 974-986. (https://doi. org/10.1111/apa.13128)

Owens JA, Thavaneswaran P, De Blasio MJ, McMillen IC, Robinson JS \& Gatford KL 2007 Sex-specific effects of placental restriction on components of the metabolic syndrome in young adult sheep. American Journal of Physiology: Endocrinology and Metabolism 292 E1879E1889. (https://doi.org/10.1152/ajpendo.00706.2006)

Rasmussen EL, Malis C, Jensen CB, Jensen JE, Storgaard $H$, Poulsen $P$, Pilgaard K, Schou JH, Madsbad S, Astrup A et al. 2005 Altered fat tissue distribution in young adult men who had low birth weight. Diabetes Care 28 151-153. (https://doi.org/10.2337/diacare.28.1.151)

Redmer DA, Luther JS, Milne JS, Aitken RP, Johnson ML, Borowicz PP, Borowicz MA, Reynolds LP \& Wallace JM 2009 Fetoplacental growth and vascular development in overnourished adolescent sheep at day 50, 90 and 130 of gestation. Reproduction 137 749-757. (https://doi. org/10.1530/REP-08-0516)

Russel AJF, Doney JM \& Gunn RG 1969 Subjective assessment of body fat in live sheep. Journal of Agricultural Science 72 451-454. (https://doi. org/10.1017/S0021859600024874) 
Trotter M \& Hixon BB 1974 Sequential changes in weight, density, and percentage ash weight of human skeletons from an early fetal period through old age. Anatomical Record 179 1-18. (https://doi.org/10.1002/ ar.1091790102)

Wallace JM 2016 Young maternal age, body composition and gestational intake impact pregnancy outcome: translational perspectives. In Obesity: Intergenerational Programming and Consequences, pp 57-80. Eds L Green \& R Hester. Berlin: Springer Science+Business Media. (https://doi. org/10.1007/978-1-4939-6386-7)

Wallace JM, Aitken RP \& Cheyne MA 1996 Nutrient partitioning and fetal growth in rapidly growing adolescent ewes. Journal of Reproduction and Fertility 107 183-90. (https://doi.org/10.1530/jrf.0.1070183)

Wallace JM, DaSilva P, Aitken RP \& Cruickshank MA 1997 Maternal endocrine status in relation to pregnancy outcome in rapidly growing adolescent sheep. Journal of Endocrinology 155 359-368. (https://doi. org/10.1677/joe.0.1550359)

Wallace JM, Bourke DA, Aitken RP \& Cruickshank MA 1999 Switching maternal dietary intake at the end of the first trimester has profound effects on placental development and fetal growth in adolescent ewes carrying singleton fetuses. Biology of Reproduction 61 101-110. (https:// doi.org/10.1095/biolreprod61.1.101)

Wallace JM, Bourke DA, Aitken RP, Palmer RM, Da Silva P \& Cruickshank MA 2000 Relationship between nutritionally-mediated placental growth restriction and fetal growth, body composition and endocrine status during late gestation in adolescent sheep. Placenta $\mathbf{2 1}$ 100-108. (https://doi.org/10.1053/plac.1999.0440)

Wallace JM, Bourke DA, Aitken RP, Leitch N \& Hay WW Jr 2002 Blood flows and nutrient uptakes in growth-restricted pregnancies induced by overnourishing adolescent sheep. American Journal of Physiology: Regulatory Integrative and Comparative Physiology 282 R1027-R1036. (https://doi.org/10.1152/ajpregu.00465.2001)

Wallace JM, Bourke DA, Aitken RP, Milne JS, Hay WW Jr 2003 Placental glucose transport in growth-restricted pregnancies induced by overnourishing adolescent sheep. Journal of Physiology 547 85-94. (https://doi.org/10.1113/jphysiol.2002.023333)

Wallace JM, Milne JS, Redmer DA \& Aitken RP 2006 Effect of diet composition on pregnancy outcome in overnourished rapidly growing adolescent sheep. British Journal of Nutrition 96 1060-1068. (https://doi. org/10.1017/BJN20061979)

Wallace JM, Milne JS, Aitken RP \& Hay WW Jr 2007 Sensitivity to metabolic signals in late-gestation growth-restricted fetuses from rapidly growing adolescent sheep. American Journal of Physiology:
Endocrinology and Metabolism 293 E1233-E1241. (https://doi. org/10.1152/ajpendo.00294.2007)

Wallace JM, Milne JS, Matsuzaki M \& Aitken RP 2008 Serial measurement of uterine blood flow from mid to late gestation in growth restricted pregnancies induced by overnourishing adolescent sheep dams. Placenta 29 718-724. (https://doi.org/10.1016/j.placenta.2008.05.006)

Wallace JM, Milne JS \& Aitken RP 2010 Effect of weight and adiposity at conception and wide variations in gestational dietary intake on pregnancy outcome and early postnatal performance in young adolescent sheep. Biology of Reproduction 82 320-330. (https://doi. org/10.1095/biolreprod.109.080069)

Wallace JM, Milne JS, Adam CL \& Aitken RP 2012 Adverse metabolic phenotype in low-birth-weight lambs and its modification by postnatal nutrition. British Journal of Nutrition 107 510-522. (https://doi. org/10.1017/S0007114511003175)

Wallace JM, Milne JS, Aitken RP \& Adam CL 2014a Impact of embryo donor adiposity, birthweight and gender on early postnatal growth, glucose metabolism and body composition in the young lamb. Reproduction, Fertility and Development 26 665-681. (https://doi. org/10.1071/RD13090)

Wallace JM, Milne JS, Aitken RP \& Adam CL 2014b Influence of birth weight and gender on lipid status and adipose tissue gene expression in lambs. Journal of Molecular Endocrinology 53 131-144. (https://doi. org/10.1530/JME-14-0123)

Wallace JM, Milne JS, Aitken RP, Redmer DA, Reynolds LP, Luther JS, Horgan GW \& Adam CL 2015 Undernutrition and stage of gestation influence fetal adipose tissue gene expression. Journal of Molecular Endocrinology 54 263-275. (https://doi.org/10.1530/JME-15-0048)

Whincup PH, Kaye SJ, Owen CJ, Huxley R, Cook DG, Anazawa S, BarrettConnor E, Bhargava SK, Birgisdottir BE, Carlsson S et al. 2008 Birth weight and risk of type 2 diabetes. A systematic review. JAMA 300 2886-2897. (https://doi.org/10.1001/jama.2008.886)

Received 24 January 2018

First decision 4 March 2018

Revised manuscript received 19 April 2018

Accepted 21 May 2018 